\title{
INFLUÊNCIA DO VOLUME DE ÁGUA UTILIZADO NO PROCESSO DE POLIMENTO DE ROCHAS ORNAMENTAIS NA QUALIDADE DO BRILHO FINAL
}

\author{
INFLUENCE OF THE VOLUME OF WATER USED IN THE POLISHING PROCESS OF \\ ORNAMENTAL ROCKS ON THE FINAL GLOSS
} \author{
mail: altoecassio@gmail.com \\ Introdução \\ Materiais e Métodos \\ Resultados e Discussões \\ Considerações Finais \\ Agradecimentos \\ Referências
}

Cássio Rigo ALTOÉ ${ }^{1}$, Leonardo Luiz Lyrio da SILVEIRA ${ }^{2}$

${ }^{1}$ Pós-graduação em Tecnologias de Produção de Rochas Ornamentais, Instituto Federal do Espírito Santo/IFES - Campus Cachoeiro de Itapemirim. Rodovia ES-482 (Cachoeiro-Alegre), Fazenda Morro Grande, Caixa Postal 727. Cachoeiro de Itapemirim, ES. E-

${ }^{2}$ Centro de Tecnologia Mineral, CETEM-MCTIC. Rod. Cachoeiro Alegre, Km 05, Bloco 10, Fazenda Morro Grande. Cachoeiro de Itapemirim-ES. E-mail: leolysil@yahoo.com.br

\begin{abstract}
RESUMO - As rochas ornamentais são materiais naturais que passam por vários processos de beneficiamento e são empregadas para fins estéticos. O polimento faz parte do processo de beneficiamento e tem como objetivo reduzir a rugosidade da superfície do material e consequentemente conferir um maior brilho. A intensidade do brilho é um dos parâmetros para quantificar a qualidade do processo de polimento. A vazão de água durante o polimento é um fator ligado diretamente ao brilho e é uma variável ainda pouco estudada. Dessa forma, obter conhecimento sobre a quantidade a ser usada pode melhorar a qualidade da rocha e reduzir o uso do recurso hídrico na produção de rochas ornamentais. O objetivo desse trabalho foi submeter três rochas ornamentais de uso consagrado ao processo de polimento realizando variações na quantidade de água, com vista a verificar a sua influência na qualidade final das superfícies. Foram usados tipos rochosos distintos: um monzogranito, um gnaisse e um diorito, conhecidos comercialmente como: Cinza Corumbá, Branco Dallas e Preto São Gabriel, respectivamente. Esses materiais foram submetidos ao polimento em três vazões diferentes. A primeira foi a quantidade usual da empresa onde se fez a pesquisa, $23,5 \mathrm{~L} / \mathrm{min}$, a segunda de $17 \mathrm{~L} / \mathrm{min}$ e a terceira de $12 \mathrm{~L} / \mathrm{min}$. Notou-se que, de modo geral, com a redução do volume de água utilizado houve um aumento do brilho. Tal constatação é fundamental para a indústria, pois é um fator ligado diretamente com a qualidade do produto além de ter uma redução do uso da água durante o processo, o que permitirá com que a cadeia produtiva de rochas ornamentais se aproxime dos preceitos da sustentabilidade.

Palavras-Chave: rochas ornamentais, polimento, brilho, água.
\end{abstract}

ABSTRACT - Dimension stones are processed natural material products used for aesthetic reasons. Polishing is part of the benefiting process and it's used to lower surface roughness of the material and consequently give it a greater gloss. The gloss is one of the parameters to measure the quality of the polishing process. Although water flow during the polishing is directly linked to the brightness of the material, it has not yet been extensively studied. So, obtaining knowledge about the amount to be used can improve the quality of the process and decrease the use of water resources when benefiting dimension stones. The objective of this study was to vary the amount of water used to polish three ornamental rocks in order to verify its influence on the final surface quality. Different types of rock were used: granite, gneiss and diorite, commercially known as: Corumbá Gray, White Dallas and Black São Gabriel. These materials were polished at three different flow rates. The first was the usual quantity used by the company where the research was conducted, $23.5 \mathrm{~L} / \mathrm{min}$, the second at $17 \mathrm{~L} / \mathrm{min}$ and the third at $12 \mathrm{~L} / \mathrm{min}$. It was noticed that, in general, reducing the amount of water increased the brightness. It's very interesting for the industry, as it improves the quality of the product and reduces the use of water resources in the process, a very important fact in terms of sustainability.

Keywords: ornamental rocks, polishing, gloss, water.

\section{INTRODUÇÃO}

O Brasil é um grande produtor e consumidor de rochas ornamentais. Em 2018, esse setor, envolvendo mercados interno, externo e comercialização de máquinas, equipamentos e insumos, movimentou cerca de US\$ 5,0 bilhões de dólares, gerando 120 mil empregos diretos e 360 mil indiretos (Chiodi Filho, 2019).

$\mathrm{O}$ parque de beneficiamento brasileiro, de serragem e polimento, tem capacidade produtiva de 90 milhões de metros quadrados por ano, o Estado do Espírito Santo se destaca como principal processador, enquanto São Paulo é o grande consumidor, recebendo $45 \%$ de toda a produção realizada no Brasil (Chiodi Filho, 2019).

As rochas ornamentais são elementos da construção civil utilizadas para revestimento em diversas aplicações (pisos, paredes, balcões, 
etc.), buscando agregar beleza estética ao ambiente.

No âmbito comercial elas são dois grandes grupos, a saber: granitos e mármores. Onde os granitos são as rochas silicáticas com predominância de quartzo e feldspato, abrangendo rochas homogêneas (granitos, sienitos, monzonitos, dioritos, charnoquitos, diabásios, basaltos, gabros, e. g.) e heterogêneas (gnaisses e migmatitos, e.g.). Os mármores são as rochas carbonáticas, incluindo calcários (sensu stricto) e dolomitos (Mattos, 2000).

As rochas ornamentais passam por três etapas de transformação: a explotação, os beneficiamentos primário e secundário. A explotação se dá pela lavra do maciço rochoso extraindo o bloco, enquanto no beneficiamento primário o bloco é serrado formando chapas e no beneficiamento secundário acontece o polimento da chapa.

Dentre as diversas formas de aplicação, o principal modo de se utilizar as rochas ornamentais é em chapa de dois centímetros de espessura. Sua superfície pode não receber nenhum tipo de tratamento (conhecida como chapa bruta), porém pode ser polida, flameada, jateada, apicoada ou escovada. Dessas alternativas a chapa polida é o tipo de acabamento mais utilizado.

Para Kaschner (1996, segundo Silveira, 2007), a etapa do polimento consiste em uma sequência de operações que busca diminuir a rugosidade superficial com foco no aumento da intensidade do brilho. Isso ocorre pelas características refletivas do material, porém é inversamente proporcional a rugosidade. Dessa forma, o brilho e lustro estão associados à eliminação da rugosidade da chapa deixada pelo beneficiamento primário e o fechamento dos minerais da rocha. Isso ocorre com o uso de abrasivos, de grãos decrescentes, que em atrito com a chapa promove seu desbaste e aumenta seu brilho.

O polimento da chapa ocorre em um contexto tribológico, como mostrado na figura 1 , com desgaste da superfície por meio de abrasão a dois corpos (rebolo abrasivo e rocha), ficando como o terceiro elemento do sistema a máquina de polir e suas variáveis de operação. Dessa forma, o tipo de politriz, as características da rocha e os tipos e formas dos abrasivos são elementos decisivos na qualidade final (Silveira, 2007).

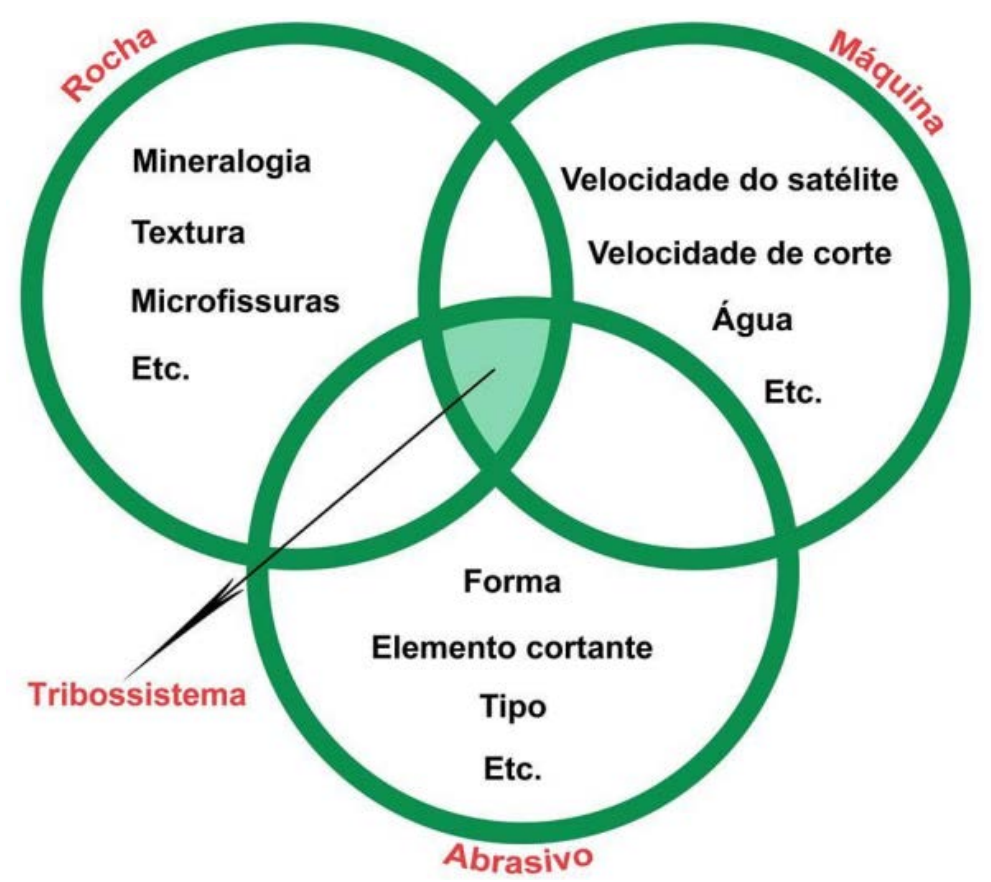

Figura 1 - Contexto tribológico do polimento de rochas ornamentais (Altoé \& Silveira, 2014).

Silveira (2007) esclarece que as variáveis desse tribossistema estão relacionadas às características da rocha, sobre sua mineralogia, textura, estrutura, porosidade, granulação, grau de micro fissuramento e grau de alteração. Ao abrasivo, de acordo com a dureza, composição do ligante, forma, tamanho e tipo do elemento abrasivo. Em relação ao processo, o tipo de equipamento e suas variáveis, velocidade de avanço, pressão aplicada, fluxo de água, velocidade de corte e tipo de movimento, também influenciam.

Para entender o brilho do polimento é importante conhecer todos esses parâmetros. 
Desde a primeira etapa da transformação do maciço em bloco até o polimento, a água é uma variável que está sempre presente. No polimento, sua função é refrigerar o processo de abrasão e promover a limpeza da lama de beneficiamento de rochas ornamentais (LBRO).

Uma politriz automática de 22 cabeçotes consome $33.000 \mathrm{~L} / \mathrm{h}$, considerando uma vazão usual média de $25 \mathrm{~L} / \mathrm{min}$ cada cabeçote. No final de um mês pode chegar a 23 milhões de litros, volume equivalente para abastecer uma cidade de aproximadamente 7.000 habitantes (Sabesp, 2018). De acordo com a Agência Nacional de Água-ANA (2017), a indústria de transformação representa o terceiro maior consumo de água no Brasil, ficando atrás do abastecimento humano e da agricultura irrigada. A intensidade do uso está ligada a fatores como: tipo de processo e de produto, a tecnologia empregada, boas práticas e maturidade de gestão.

Recentemente observa-se uma preocupação maior com o uso eficiente da água nos processos industriais como estratégia competitiva, sobretudo indústrias que atendem o mercado externo ou que estão em zonas de escassez. É importante combater o desperdício de água com métodos e tecnologias para reduzir seu consumo, aumentar a reciclagem e o reuso, ou seja, a economia circular da água. Seu uso eficiente e descarte adequado, além de ganhos financeiros, podem gerar oportunidades. Uma análise recente da Ellen McArthur Foundation mostrou que até 2050, um desenvolvimento voltado para a economia circular, pode render a um país em desenvolvimento benefícios equivalente a 30\% do seu PIB anual (Cebds, 2018).

Essa redução no consumo de água tem como resultado a otimização do trabalho. Segundo Souza Jr (2005) a otimização se mostra por determinar a melhor correlação entre as variáveis mesmo sem testar todas as possibilidades e sem onerar o processo.

$\mathrm{Na}$ indústria 4.0, as empresas buscam estratégias com tecnologia de ponta, ligadas a internet tornando os sistemas mais flexíveis onde as máquinas usam auto otimização, auto configuração e até mesmo inteligência artificial para proporcionar eficiências de custo muito superiores e bens ou serviços de melhor qualidade (Santos et al., 2018). Um sistema de automação para controlar as vazões de água de acordo com a necessidade de cada material seria um grande avanço no setor.

O objetivo desse trabalho foi analisar o processo de três tipos de rochas ornamentais de uso consagrado ao processo de polimento, realizando variações na quantidade de água e examinando suas características intrínsecas, com vista a verificar a sua influência na qualidade final da superfície.

\section{MATERIAIS E MÉTODOS}

Para realização desse trabalho foram escolhidos três tipos de rochas ornamentais de uso consagrado e com características petrográficas (físicomecânicas, texturais e estruturais) distintas, de forma que os resultados obtidos podem ser referenciais para rochas com características próximas. Foi escolhido um monzogranito, um gnaisse e um diorito, conhecidos comercialmente como: Cinza Corumbá, Branco Dallas e Preto São Gabriel, respectivamente (Figura 2).

A tabela a seguir reúne as informações dos materiais utilizados na pesquisa com características físico-mecânicas, composição mineralógica, classificação e textura (Tabela 1).
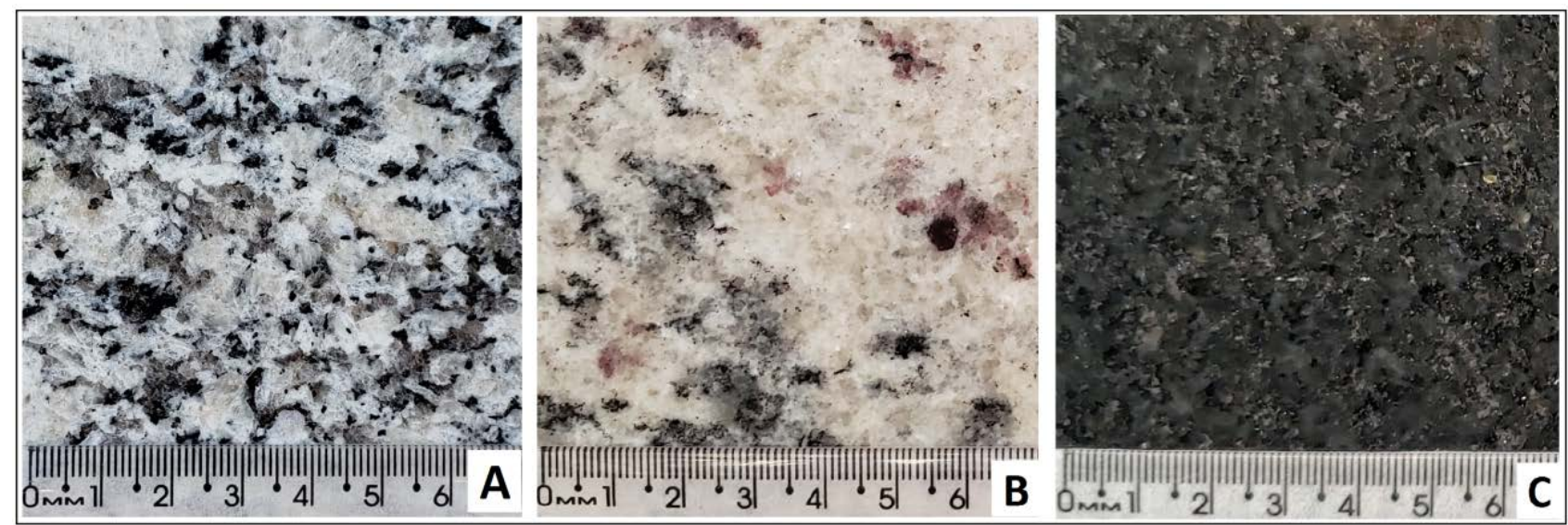

Figura 2 - Rochas utilizadas na pesquisa: monzogranito Cinza Corumbá (A), gnaisse Branco Dallas (B) e diorito Preto São Gabriel (C).

São Paulo, UNESP, Geociências, v. 39, n. 3, p. 875 - 884, 2020 
Tabela 1 - Informações sobre as rochas utilizadas (adaptado de Alencar, 2013).

\begin{tabular}{|c|c|c|c|}
\hline Nome comercial: & Cinza Corumbá & Branco Dallas & Preto São Gabriel \\
\hline \multicolumn{4}{|c|}{ CARACTERÍSTICAS FÍSICO-MECÂNICAS } \\
\hline Densidade Aparente $\left(\mathrm{kg} / \mathrm{m}^{3}\right)$ & 2673 & 2627 & 2960 \\
\hline Porosidade Aparente (\%) & 0,93 & 0,86 & 0,96 \\
\hline Compressão Uniaxial (Mpa) & 130,20 & 140,81 & 113,70 \\
\hline Compressão após gelo/degelo (Mpa) & 131,40 & - & 121,30 \\
\hline Absorção d’água (\%) & 0,35 & 0,33 & 0,33 \\
\hline Flexão (Mpa) & 10,18 & 11,44 & 14,10 \\
\hline Coeficiente Dilatação Térmica Linear $\left(\mathrm{mm} / \mathrm{m}^{\circ} \mathrm{C} .10^{3}\right)$ & 5,20 & - & 7,80 \\
\hline \multicolumn{4}{|c|}{ COMPOSIC̨ÃO MINERALÓGICA } \\
\hline Microclina micropertítica & $33 \%$ & - & - \\
\hline Microclima mesopertítica & - & $25-30 \%$ & - \\
\hline Plagioclásio & $30 \%$ & $5 \%$ & $60 \%$ \\
\hline Quartzo & $20 \%$ & $10-15 \%$ & $5 \%$ \\
\hline Biotita & $12 \%$ & $<5 \%$ & $15 \%$ \\
\hline Hiperstênio & - & - & $15 \%$ \\
\hline Hornblenda & - & - & $5 \%$ \\
\hline Granada & - & $5 \%$ & - \\
\hline Pseudomorfos de cordierita & - & $<5 \%$ & - \\
\hline Acessórios & $5 \%$ & - & - \\
\hline CLASSIFICACÃO & Monzogranito & Gnaisse & Diorito \\
\hline TEXTURA & $\begin{array}{c}\text { Fanerítica } \\
\text { inequigranular } \\
\text { porfirítica }\end{array}$ & $\begin{array}{l}\text { Granolepido- } \\
\text { blástica }\end{array}$ & $\begin{array}{c}\text { Fanerítica } \\
\text { equigranular fina }\end{array}$ \\
\hline
\end{tabular}

A empresa Luarte Comércio de Pedras, onde se realizou a pesquisa, está localizada no município de Vargem Alta - ES atua no processamento de rochas ornamentais, serrada e polimento. Sua capacidade produtiva é de $20.000 \mathrm{~m}^{2} /$ mês e um variado tipo de rochas de diferentes tonalidades.

Para realização do polimento foi utilizada uma politriz automática italiana da marca FMeccanica modelo FLG2200 (Figura 3). Esse tipo de politriz com esteira é o mais usado no mercado atualmente. Seu funcionamento segue uma linha de produção, sendo rápida e segura durante todo o processo de polimento.

Depois do processo de serragem, as chapas brutas são submetidas ao processo de polimento. Elas são movimentadas através da politriz por uma esteira. A Figura 3A mostra o início do polimento, onde a chapa bruta é conduzida para dentro da politriz, enquanto 22 cabeçotes com seis abrasivos cada um passam transversalmente sobre a chapa, como mostrado na Figura 3B. Esses cabeçotes são sustentados por mandris, acoplados em duas traves, cada uma com 11 cabeçotes (Figura 3C). No final do polimento a chapa sai polida e um secador retira o excesso de água (Figura 3D).

As traves ficam suspensas pela base da politriz através do contato de pastilhas de grafite de alta dureza banhado em óleo. As traves proporcionam aos cabeçotes o movimento sobre a chapa, sustentam os mandris, cabos elétricos e as tubulações de água e ar. Já os mandris sustentam os cabeçotes e o motor que o faz girar. Sua principal função é fazer o movimento vertical (sobe e desce) dos cabeçotes no início e no final de cada chapa. Seu acionamento ocorre através de válvulas pneumáticas. A politriz possui 22 painéis (Figura 4) de comando individual de cada cabeçote. Nos painéis existem os comandos do motor: ligar e desligar; do cabeçote: subir, descer e trocar abrasivo; e um dos principais comandos para o polimento que é o regulador da pressão, que fica visível em um manômetro analógico.

Outro comando essencial para o bom funcionamento da politriz é o painel de comando central (Figura 5). Esse computador marca e regula diversos parâmetros da máquina. A velocidade da esteira e das traves, o momento em que os cabeçotes descem e sobem sobre a chapa, ligar água e outros, além de mostrar uma visão geral da politriz em funcionamento com os cabeçotes que estão funcionando ou parados, as medidas e a posição das chapas ao longo da esteira. 

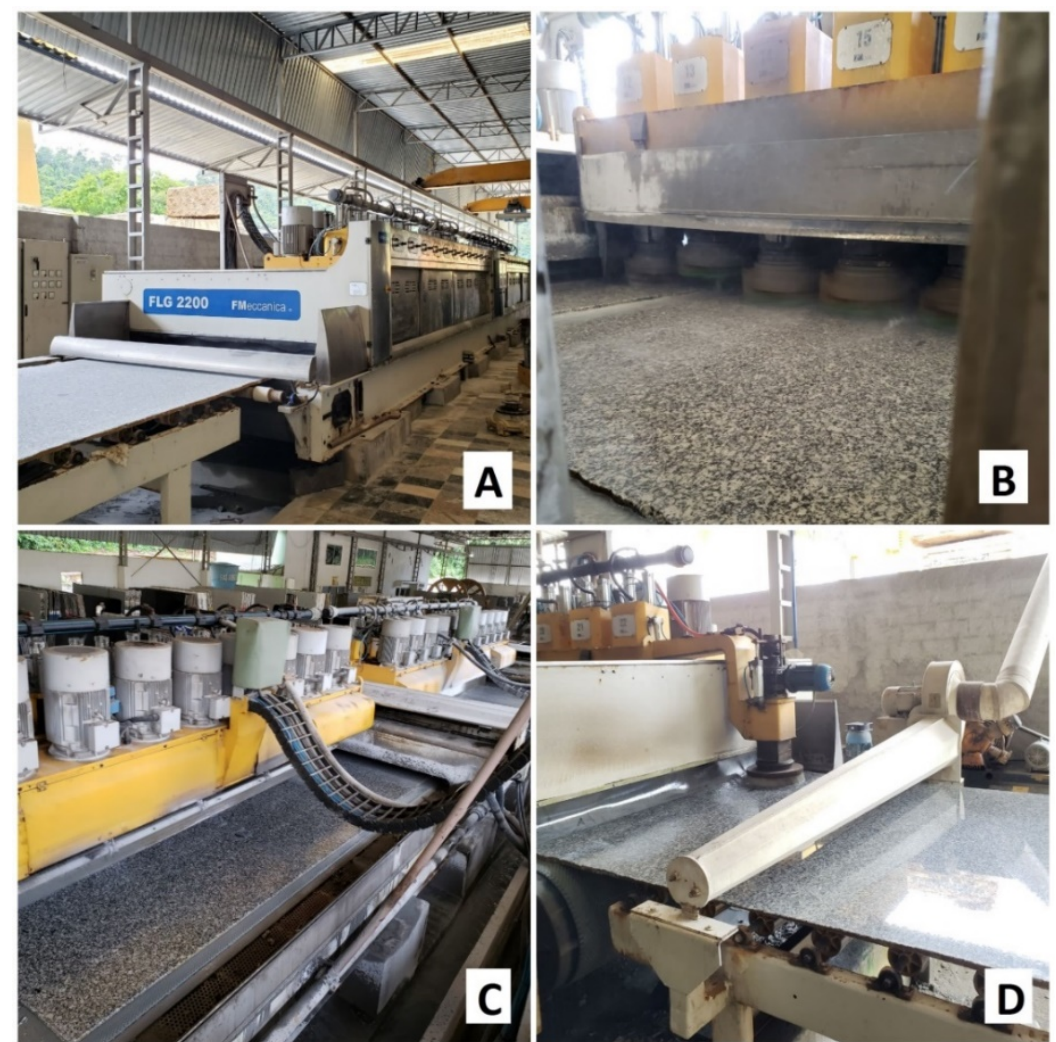

Figura 3 - Politriz utilizada na pesquisa.

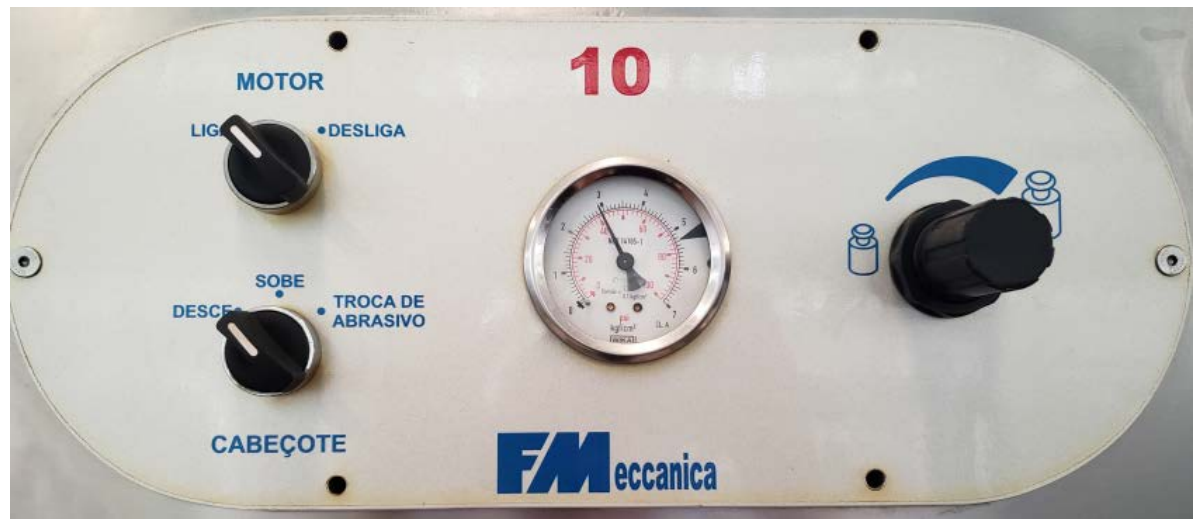

Figura 4 - Painel de comando dos cabeçotes.

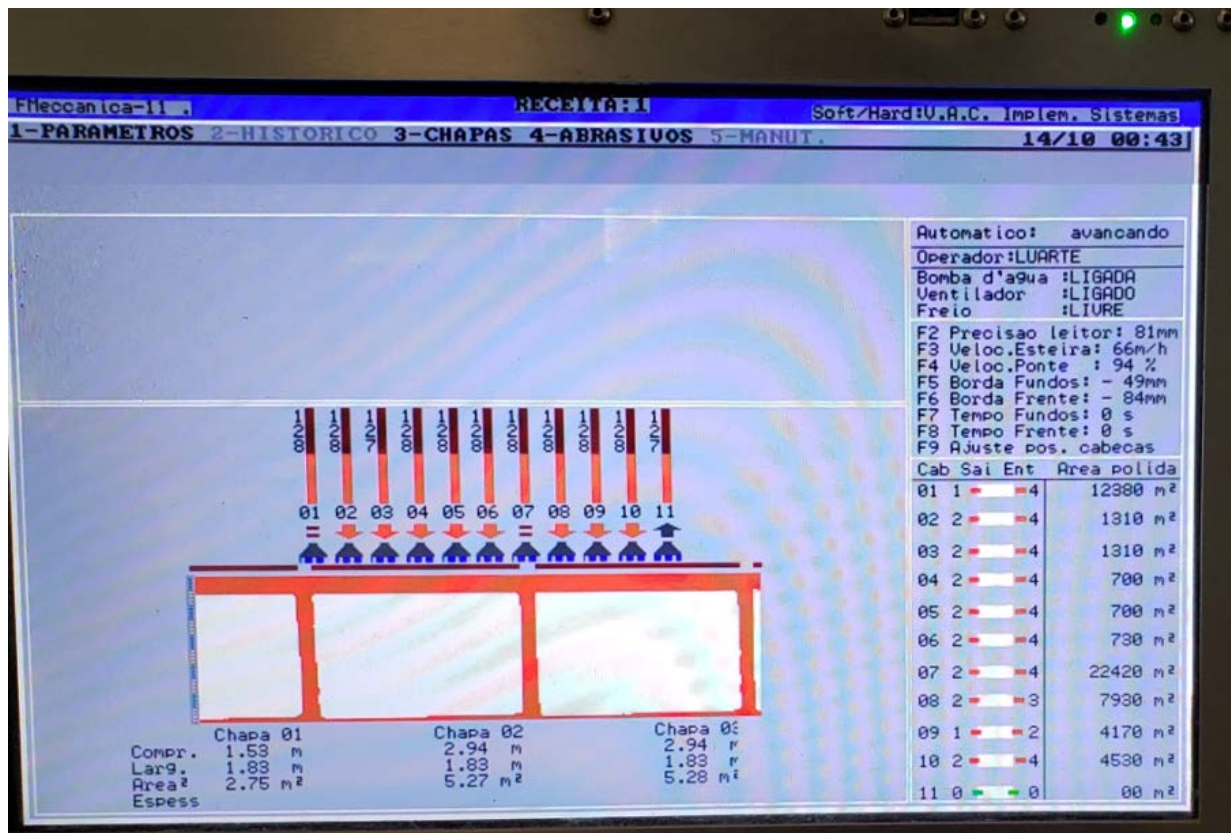

Figura 5 - Painel de comando central da politriz. 
Os cabeçotes de polimento, também conhecidos na indústria por satélites, são da marca Comes, com encaixe de seis abrasivos cada um. Os abrasivos são divididos entre diamantados (ficam na primeira parte da politriz), resinóides e lustro (na segunda parte).

Os grãos e tipos dos abrasivos com seus respectivos cabeçotes utilizados durante 0 polimento estão indicados a seguir (Tabela 2).

Em uma vista frontal da politriz (Figura 6) é possível observar a localização de seus componentes principais: painel de comando dos cabeçotes (A), painel de comando central (B), o cabeçote com os abrasivos e a água do polimento (C) e as duas traves (D) que sustentam os mandris com os cabeçotes.

Tabela 2 - Abrasivos utilizados no polimento.

\begin{tabular}{c|c|c|c|c|c}
\hline \multicolumn{4}{c|}{ Trave 1 } & \multicolumn{3}{c}{ Trave 2 } \\
\hline Satélite n $^{\circ}$ & Abrasivo Grão & Tipo & Satélite n & Abrasivo Grão & Tipo \\
\hline 1 & $\mathrm{~m} 6$ & Diamantado & 12 & 220 & Resinóide \\
\hline 2 & $\mathrm{~m} 7$ & Diamantado & 13 & 320 & Resinóide \\
\hline 3 & $\mathrm{~m} 8$ & Diamantado & 14 & 400 & Resinóide \\
\hline 4 & $\mathrm{~m} 9$ & Diamantado & 15 & 600 & Resinóide \\
\hline 5 & $\mathrm{~m} 11$ & Diamantado & 16 & 600 & Resinóide \\
\hline 6 & $\mathrm{~m} 13$ & Diamantado & 17 & 800 & Resinóide \\
\hline 7 & $\mathrm{~m} 15$ & Diamantado & 18 & 1200 & Resinóide \\
\hline 8 & parado & - & 19 & 1500 & Resinóide \\
\hline 9 & $\mathrm{~m} 18$ & Diamantado & 20 & 1500 & Resinóide \\
\hline 10 & $\mathrm{~m} 20$ & Diamantado & 21 & Lustro & - \\
\hline 11 & $\mathrm{~m} 22$ & Diamantado & 22 & Lustro & - \\
\hline
\end{tabular}

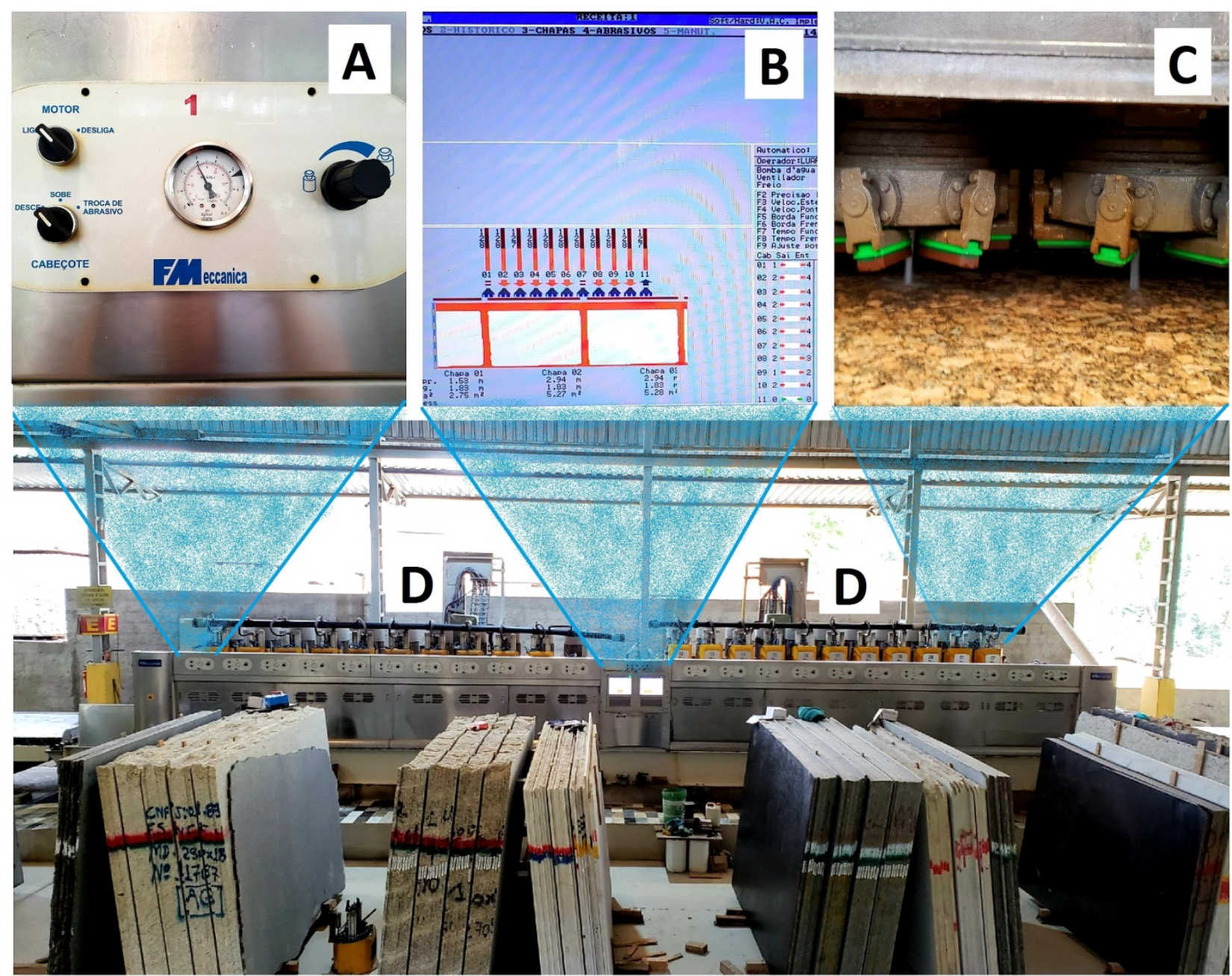

Figura 6 - Principais componentes da politriz. 
Para controlar a vazão de água foi utilizado um hidrômetro de turbina eletrônico modelo k24 (Figura7A), que opera com vazão entre 10 e 120 $\mathrm{L} / \mathrm{min}$ com precisão de $\pm 1 \%$. Para verificar se o equipamento estava devidamente calibrado, encheu-se um balde de 10 litros de água em um intervalo de tempo e verificou-se que a vazão no equipamento estava correta. A medição do brilho foi feita com aparelho Glossmeter modelo microTRI-gloss (Figura 7B), da marca BYK-Gardner.
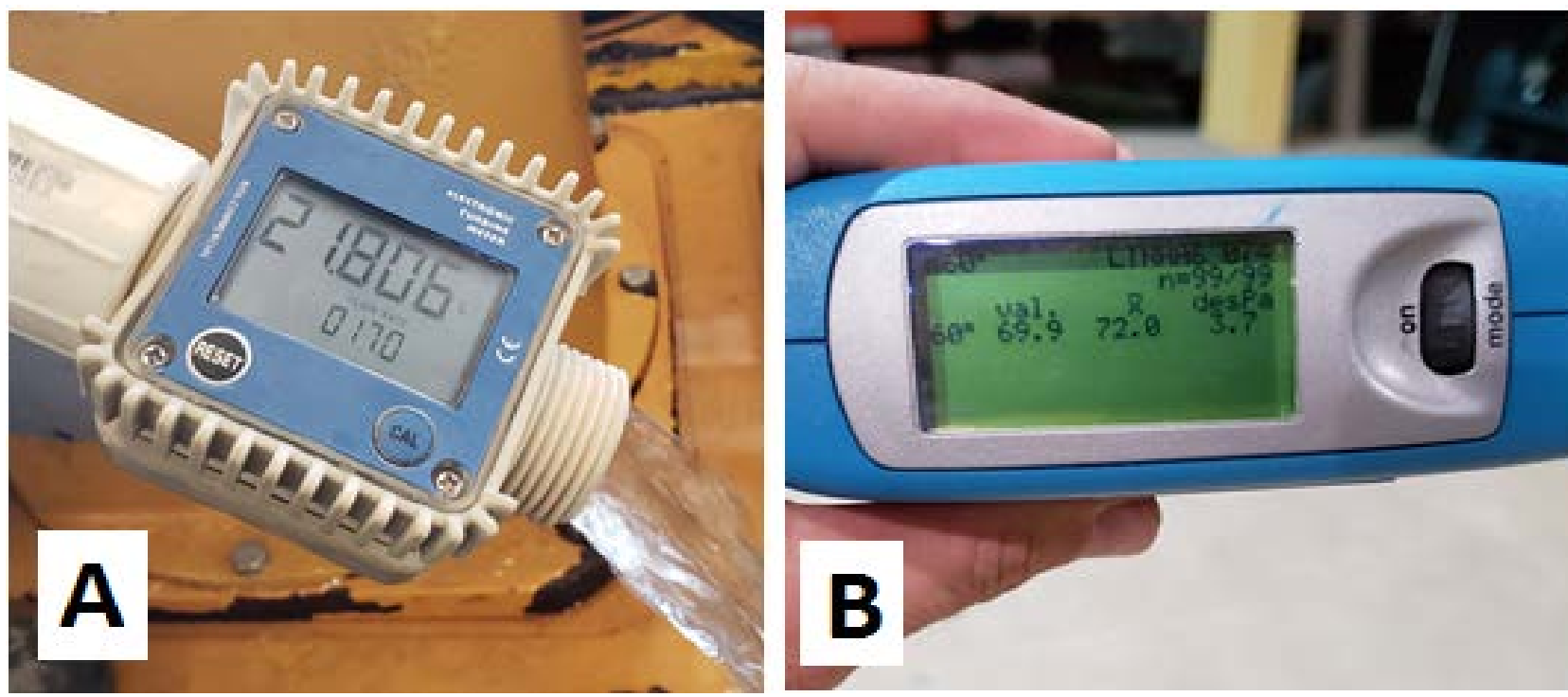

Figura 7 - Medidor de vazão (A) e medidor de brilhos (B) utilizados na pesquisa.

Para avaliar a condição do brilho do polimento após a redução da quantidade de água, as vazões foram definidas em normal, original da máquina em serviço (23,5 L/min), uma média (17 L/min) e outra baixa (12 L/min).

Entende-se que os primeiros abrasivos tem função de corte, sua abrasão com a rocha é maior e gera mais resíduo. Então não é viável diminuir a quantidade de água nesses, pois certamente iria comprometer seu rendimento e não alteraria o brilho. Dessa forma a redução da vazão de água aconteceu a partir do cabeçote 14 , com abrasivo de grão 400, até o 22 com lustro.

Para cada vazão foram usadas duas chapas de cada material, ou seja, na vazão 23,50 L/min foram polidas duas chapas de Corumbá, Dallas e Preto, depois a vazão foi alterada para $17 \mathrm{~L} / \mathrm{min}$ e houve o polimento de mais duas chapas de cada litotipo. Por último, a vazão de $12 \mathrm{~L} / \mathrm{min}$ com mesmo procedimento. Em resumo, a cada vazão foram submetidas ao polimento seis chapas, gerando um total de 18 chapas para a realização do experimento.

A regulagem da vazão ocorreu por meio da acoplagem do medidor entre o registro, que fica na parte superior do mandril, e o cano que leva água ao cabeçote. No cotidiano da empresa não são realizadas mudanças nas vazões, todos os registros ficam aberto no máximo. A princípio verificou-se a vazão original da máquina, que foi a maior $(23,5$ $\mathrm{L} / \mathrm{min}$ ), na segunda etapa, os registros foram regulados para exercer uma vazão média (17 $\mathrm{L} / \mathrm{min}$ ) e na terceira etapa foi regulado para vazão baixa (12 L/min).A velocidade da esteira da politriz foi de $116 \mathrm{~cm} / \mathrm{min}$ ou $70 \mathrm{~m} / \mathrm{h}$, enquanto a trave apresentava oito ciclos por minuto. Sendo um ciclo entendido como uma ida e volta ao ponto inicial.

As chapas das rochas utilizadas foram materiais considerados de primeira, ou seja, não possuíam feições, como os xenólitos, comercialmente chamados de "mula". Foram serradas em tear de fio diamantado e suas dimensões são de 2,95 x 1,95 metros e dois centímetros de espessura.

Das três rochas, no diorito Preto São Gabriel e no gnaisse Branco Dallas normalmente é aplicado um líquido intensificador de brilho e cor depois do polimento. Para não haver alteração no resultado abriu-se mão do uso desse produto.

A medição do brilho foi feita em toda chapa em pontos distintos, buscando abranger uma homogeneidade máxima, deixando o resultado mais real possível. Em cada uma o brilho foi medido 500 vezes, assim nas 18 chapas foram 9.000 medições.

\section{RESULTADOS E DISCUSSÃO}

A partir do polimento foi possível obter o brilho dos materiais nas vazões definidas. No gráfico (Figura 8) é possível ver os valores encontrados para 0 monzogranito Cinza 
Corumbá na relação vazão e brilho. Com a vazão inicial de 23,5 L/min o brilho ficou em 72,9 GU (gloss units, em português: unidade de brilho); ao diminuir a vazão para $17 \mathrm{~L} / \mathrm{min}$ houve um aumento de brilho para 75,4 GU e com a menor vazão, de $12 \mathrm{~L} / \mathrm{min}$, o brilho ficou em 75,8 GU. Da vazão inicial para a final o ganho de brilho ficou em 3,98\%. No gráfico (Figura 9) é possível verificar os valores encontrados para o gnaisse Branco Dallas. Com a vazão inicial (maior vazão), o Branco Dallas teve um brilho de 72,2 GU; com a vazão média 73 GU e com a vazão mais baixa, $12 \mathrm{~L} / \mathrm{min}$ o brilho subiu para 74,7 GU. Um ganho de 3,46\%. Para o diorito Preto São Gabriel temos os seguintes resultados no gráfico abaixo (Figura 10).

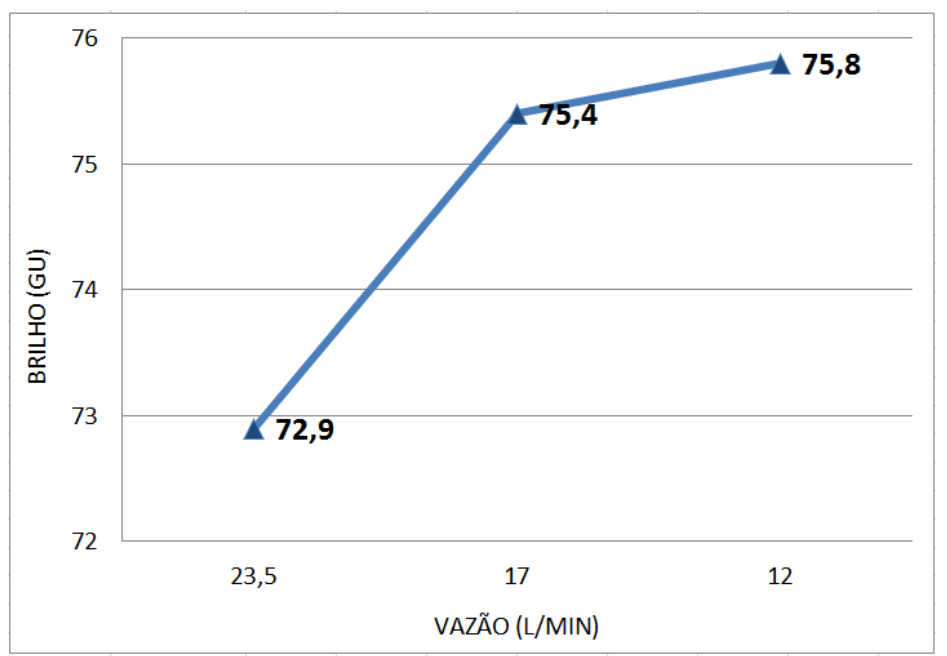

Figura 8 - Relação vazão e brilho Cinza Corumbá.

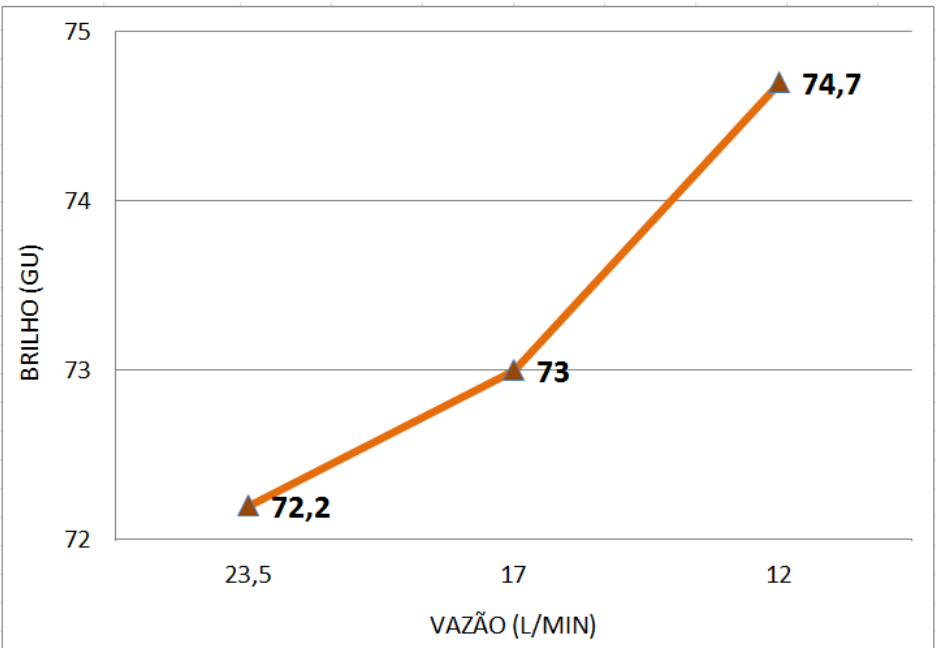

Figura 9 - Relação vazão e brilho Branco Dallas.

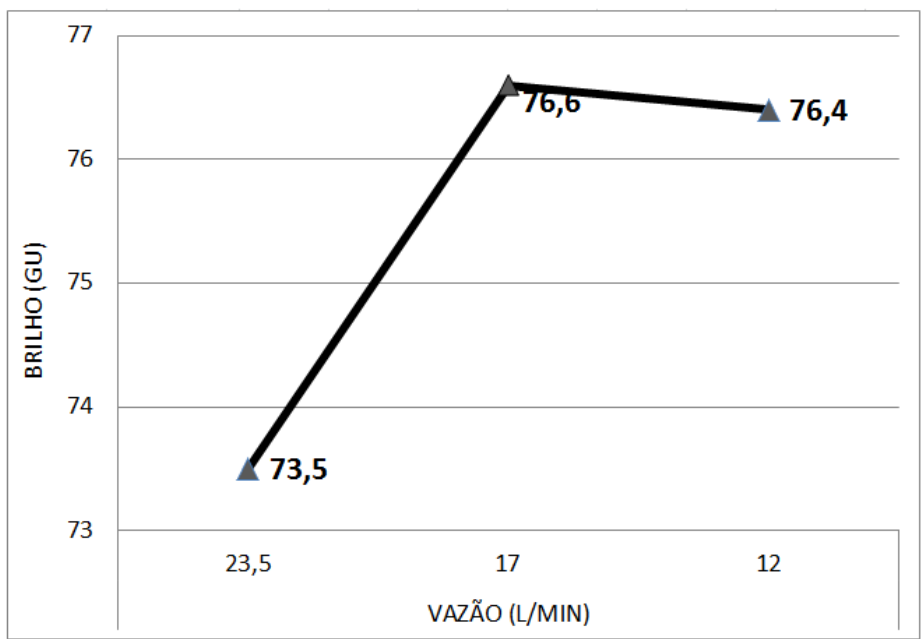

Figura 10 - Relação vazão e brilho Preto São Gabriel. 
No diorito Preto São Gabriel o brilho inicial foi de 73,5 GU; subiu para 76,6 GU na vazão de $17 \mathrm{~L} / \mathrm{min}$ e na vazão de $12 \mathrm{~L} / \mathrm{min}$, ficou com 76,4 GU. Da vazão normal utilizada na empresa para a vazão média o ganho de brilho foi de $4,22 \%$. Se comparar a vazão normal com a menor vazão teve um aumento de 3,95\%.

No monzogranito Cinza Corumbá e no diorito Preto São Gabriel ocorreu um maior aumento do brilho na primeira diminuição da vazão de água (23,5 para $17 \mathrm{~L} / \mathrm{min}) ; 3,43 \%$ e $4,22 \%$ respectivamente; enquanto o gnaisse Branco Dallas teve um aumento de 1,11\%.

Da segunda vazão utilizada, $17 \mathrm{~L} / \mathrm{min}$, para a terceira, $12 \mathrm{~L} / \mathrm{min}$, o monzogranito Cinza Corumbá elevou o brilho em $0,53 \%$; o gnaisse Branco Dallas 2,33\% e o diorito Preto São Gabriel teve uma pequena queda no brilho de $0,26 \%$.

Comparando a vazão inicial e a final houve um ganho de brilho acima de 3,46\% em todos os materiais, sendo que o monzogranito Cinza Corumbá e o diorito Preto São Gabriel tiveram quase $4 \%$ de ganho. Esse resultado favorável pode ser resultado da boa relação entre a baixa quantidade de água e um aumento da interação dos minerais com o abrasivo.

Do ponto de vista tribológico a água é um elemento ligado ao processo de polimento pela máquina. Segundo Monteiro (2014) ela age como lubrificante, onde o principal propósito é reduzir a temperatura de superfície e da ferramenta de corte. Marcon et al. (2012) diz que o acúmulo de água em um abrasivo diminui o poder de corte devido ao fenômeno de aquaplanagem.

Dessa forma o excesso de água pode comprometer a ação dos abrasivos de fechamento (a partir do grão 400), visto que sua superfície é mais lisa do que a dos abrasivos de corte, então a água reduz o contato do abrasivo com a rocha. Dessa forma a redução da quantidade de água melhorou o polimento e aumentou o brilho nos três materiais.

A redução da água aumenta a temperatura do processo. De acordo com Tylczak (1992, segundo Silveira, 2007) a temperatura tem influência sobre a resistência do desgaste dos materiais, já que o aumento da temperatura diminui a dureza do mineral. Essa dureza pode estar fazendo com que o mineral ao invés de ser desbastado seja compactado a superfície da rocha, diminuindo a rugosidade e melhorando o brilho.

Quanto às rochas utilizadas, as três possuem propriedades físico-mecânicas, composição mineralógicas, classificação e textura distintas. Todas obtiveram um ganho de brilho em relação à vazão inicial. Esse resultado indica que mesmo materiais de características diferentes tiveram uma resposta positiva ao brilho com a redução do volume de água.

Seraco (2016) diz que ainda existem muitas dúvidas sobre a quantidade de água e os fenômenos físico-químicos, que ocorrem com o comportamento da temperatura da interface rocha-rebolo abrasivo.

Semelhante a essa ideia, na área da odontologia, Cardoso et al. (2006) diz que existem várias dúvidas sobre um sistema mais ou menos refrigerado. $\mathrm{O}$ calor gerado pelos instrumentos rotatórios na fase do polimento pode ser altamente interessante sob o ponto de vista físico-estético, já que o acabamento e polimento sem refrigeração promovem maior lisura superficial, por consequência maior brilho.

A economia de água, quando foi reduzida a vazão de $23,5 \mathrm{~L} / \mathrm{min}$ para $12 \mathrm{~L} / \mathrm{min}$ entre os cabeçotes 14 e 22, como realizado nesse trabalho, gerará uma redução mensal de quase 7 milhões de litros de água. Essa mudança na gestão do processo de polimento representa um marco no uso eficiente da água, transformando a forma de produzir mais sustentável podendo também gerar vantagens competitivas (marketing), sobretudo a empresas que atendem o mercado externo.

Para realizar a regulagem da quantidade de água, os registros foram fechados de forma manual. Então, uma forma de adentrar ao modelo de gestão da indústria 4.0 seria programar sensores de vazões conectados ao sistema da politriz e a internet, interagindo uns com os outros em tempo real facilitando as mudanças. Dessa forma, otimizando o trabalho e melhorando a qualidade final do produto.

\section{CONSIDERAÇÕES FINAIS}

A partir dos resultados obtidos com a produto, o brilho, além de reduzir o consumo de realização desse artigo, é visível que uma pequena mudança no sistema produtivo, na vazão d’água, pode melhorar a qualidade final do água, um bem finito.

Com a diminuição da quantidade de água no polimento, o monzogranito Cinza Corumbá 
chegou a ter um ganho de 3,98\% no brilho da chapa, o gnaisse Branco Dallas 3,46\% e o diorito Preto São Gabriel 4,22\% com as vazões utilizadas nesse trabalho.

As características intrínsecas das rochas não apresentaram relações diretas com a diminuição da vazão e o brilho obtido, visto que elas possuíam propriedades distintas e tiveram um ganho de brilho semelhante. Otimização do trabalho, sustentabilidade, economia circular, entrar na indústria 4.0, marketing e maior competitividade com um produto de melhor qualidade, são características das empresas que buscarem essa ideia de trabalho.

Como continuação dessa pesquisa propõe-se utilizar outras vazões ainda menores e verificar a relação entre essa redução e a produtividade dos abrasivos.

\section{AGRADECIMENTOS}

Os autores agradecem aos engenheiros Victor Moza Ponciano e Wana Favero Gaburo Dorigo que contribuíram nas visitas à indústria. Agradecem também a empresa Luarte Comércio de Pedras que disponibilizou a politriz e funcionários para realização dos testes.

\section{REFERÊNCIAS}

ANA - AGÊNCIA NACIONAL DE ÁGUAS (). Água na indústria: uso e coeficientes técnicos. Ministério do Meio Ambiente (MMA). Superintendência de Planejamento de Recursos Hídricos (SPR). Brasília - DF. 37 p., 2017.

ALENCAR, C.R.A. Manual de caracterização, aplicação, uso e manutenção das principais rochas comerciais no Espírito Santo: rochas ornamentais. Instituto Euvaldo Lodi - Regional do Espírito Santo. Cachoeiro de Itapemirim/ES: IEL, 242 p.: il. 2013.

ALTOÉ, T.P. \& SILVEIRA, L.L. Tribologia aplicada ao desenvolvimento metodológico de ensaio para rochas ornamentais. In: JORNADA DE INICIAÇÃO CIENTÍFICA, XXII Cachoeiro de Itapemirim. 2014. Atas... Cachoeiro de Itapemirim: CETEM, 2014.

CARDOSO, P.C. Efeito da refrigeração na rugosidade superficial e dureza das resinas compostas durante o procedimento de polimento. Revista Dental Press Estét. v. 3, n. 1, p. 20-26, jan./fev./mar. 2006.

CEBDS - Conselho Empresarial Brasileiro para o Desenvolvimento Sustentável. Guia sobre economia circular de água. Conselho empresarial brasileiro para o desenvolvimento sustentável. Rio de Janeiro, RJ. 2018. Disp. em: $<$ http://cebds.org/wpcontent/uploads/2018/04/Guia_Agua_SUMEX_ALTA.pdf $>$. Acesso em: 20 de out. de 2019.

CHIODI FILHO, C. O Setor Brasileiro de Rochas Ornamentais. Panorama Setorial. Perfil das atividades setoriais no Brasil. Abirochas. Outubro/2019. Disp. em: $<$ https://www.abirochas.co m.br/wpcontent/uploads/2018/06/Panorama/Perfil_das_Atividades_Set oriais_Brasil_2018.pdf>. Acesso em: 07 de out. de 2019.

KASCHNER, D. Tecnologias para beneficiamento. In: ENCONTRO DO CENTRO-OESTE SOBRE GRANITOS, MÁRMORES E PEDRAS ORNAMENTAIS, II, Goiânia, 36, p., 1996. Atas...Goiânia.

MARCON, D.B.; PEITER, C.C.; CASTRO, N.F. Utilização de fio diamantado na lavra de granitos comerciais. In: JORNADA DE INICIAÇÃO CIENTÍFICA, XX, Cachoeiro de Itapemirim, 2012. Atas... Cachoeiro de Itapemirim: CETEM, 2012

MATTOS, I.C. Uso/adequação e aplicação de rochas ornamentais na construção civil. Cartilha de aplicação de rochas ornamentais. Brasília-DF. 2000. Disp. em: $<$ http://www.fiec.o rg.br/sindicatos/simagran/artigos_pales tras/Uso_Adequacao1.htm.
MONTEIRO, C.F.F. Corte de Pedra por Fio Diamantado. Azurém, 2014. Dissertação (Mestrado), Escola de Engenharia, Departamento de Engenharia Mecânica, Universidade do Minho. Portugal. 2014. Disp. em: < http://hdl.handle.net/1822/34349.

SABESP. Companhia de Saneamento Básico do Estado de São Paulo. Uso Racional da Água: Dicas de economia. 2018. Disp. em: < http://site.sabesp.com.br/site/interna/Default.aspx? secaoId $=1$ 40>. Acesso em 07 de jan. 2020.

SANTOS, B.P. Indústria 4.0: desafios e oportunidades. Rio de Janeiro. Revista Produção e Desenvolvimento, v. 4, n. 1, p. 111-124, RJ. 2018.

SERACO, I.P. Aspectos relacionados ao atrito no processo de polimento de rochas ornamentais. In: JORNADA DE INICIAÇÃO CIENTÍFICA, XXIV, Cachoeiro de Itapemirim, 2016. Atas... Cachoeiro de Itapemirim: CETEM, 2016.

SILVEIRA, L.L. Polimento de rochas ornamentais: um enfoque tribológico ao processo. São Carlos, 2007. Tese (Doutorado), Escola de Engenharia de São Carlos Universidade de São Paulo.

SOUZA JR, D.A. Optimization and design of three dimensional tubular steel covering structure formed by crossed members using genetic algorithm. Uberlândia, 2005, 145 p. Tese (Doutorado), Universidade Federal de Uberlândia. TYLCZAK, J.H. Abrasive wear. In: ASM Handbook Friction, lubrification and wear technology, v. 18, p. 184-190, 1992

Submetido em 18 de abril de 2020 Aceito para publicação em 11 de agosto de 2020 